\title{
Vibrations Evaluation of Functionally Graded Porous Beams in Thermal Surroundings by Generalized Differential Quadrature Method
}

\author{
Mahdi Khakpour, ${ }^{1}$ Yousef Bazargan-Lari $\mathbb{D}^{1},{ }^{1}$ Parham Zahedinejad, ${ }^{2}$ \\ and Mohammad- Javad Kazemzadeh-parsi ${ }^{1}$ \\ ${ }^{1}$ Department of Mechanical Engineering, Shiraz Branch, Islamic Azad University, Shiraz, Iran \\ ${ }^{2}$ Department of Mechanical and Energy Engineering, North Texas University, Denton, USA \\ Correspondence should be addressed to Yousef Bazargan-Lari; bazarganlari@iaushiraz.ac.ir
}

Received 31 December 2021; Revised 22 January 2022; Accepted 26 January 2022; Published 23 February 2022

Academic Editor: Jiaqiang E

Copyright (c) 2022 Mahdi Khakpour et al. This is an open access article distributed under the Creative Commons Attribution License, which permits unrestricted use, distribution, and reproduction in any medium, provided the original work is properly cited.

\begin{abstract}
This study investigates how to obtain the natural frequency of functionally graded porous beams simply supported on an elastic substrate in thermal surroundings by the theory of third-order shear deformation. Temperature constantly changes in the beam thickness direction and step with the distribution of volume fraction power law of the ingredient has been affected on the material attributes. The distribution of uniform porosity at the pass phase is examined. To achieve the equations of governing, Hamilton's principle was carried out. To discretize these equations, the generalized differential quadrature method has been used. First, the approach's convergence is shown. Comparison with the results of other articles was performed for validation. Here, the impacts of numerous factors like index of power law, heat field type, temperature difference, slenderness ratio, and porosity coefficient and elastic substrate factors of a functionally graded porous beam on the natural frequencies were studied for simple boundary conditions. In addition to displaying these parameters' impact on the beam's thermomechanical evaluation, the conclusions also confirm the accuracy of the numerical technique used.
\end{abstract}

\section{Introduction}

Laminated composites are widely utilized in diverse equipment and structure, especially thermomechanical loads, due to their mechanical and thermal suitability. Due to the discontinuity of the material and many changes in the location of the layers, the stress concentration is created in this region, which will eventually lead to the separation of the layers from each other. In addition, many changes in the plastic in the boundary layer cause cracks and growth in the material [1]. Here, functionally graded (FG) materials are a suitable alternative to these materials. The development and expansion of FG materials in recent years have attracted the attention of engineers and researchers. These materials are used due to their multiple applications in the aerospace industry, aerospace engineering, and heat shields; therefore, it is necessary to have a detailed analysis of the dynamic behavior of FG materials. This need led to research on FG graded structures and beams and their free vibrations using various beam theories.

Several researchers like Alshorbagy et al. [2], Pradhan and Chakraverty [3], and Jin and Wang [4] have utilized the classical beam theory for FG beams with a large slenderness ratio. For FG beams with a medium slenderness ratio, this theory considers the deformation to be less than the actual value and ignores the transverse shear deformation effects and estimates the natural frequencies to be larger than the actual value. Timoshenko's theory overcomes this classical theory limitation in research by researchers, for example, Li [5], Wu et al. [6], and Katili et al. [7]. A correction parameter is required in this theory because of the zero shear stress violation at the top and bottom of the beam. 
The high-order shear deformation theory is applied for better predicting the behavior of the beam and other structures. As mentioned before, this research was directed towards the analysis of the vibrations of FG beams using these theories. Wen and Zeng analyzed the vibrations of the beams utilizing the high-order finite element [8]. Şimşek evaluated the principle frequencies of FG beams making use of the theories of various high-order and different boundary conditions [9]. Kazemzadeh-Parsi et al. investigated free vibration of FG plates applying the theory of high-order shear deformation [10].

In engineering issues and applications, beams are usually supported along their length on a substrate and interact with that substrate. Studies about the impact of elastic substrate parameters on the free vibrations of isotropic beams were carried out by Chen [11] and Malekzadeh and Karami [12]. Additionally, several studies have been conducted by Aghazadeh et al. [13], Akbaş [14], and Mohseni and Shakouri [15] on the bending and free vibration of FG beams depending on one- and two-parametric elastic substrates and based on different theories and solution methods.

As we can see, there are few studies on the FG beams in thermal surroundings. Several studies were done with the thermal behavior approach for showing the advantages of FG materials. Vibrations of an FG beam located in a thermal surrounding were considered by Mahi et al. utilizing highorder shear deformation theory and analytical method [16]. An analytical technique was used by Trinh et al. for investigating the behaviors of buckling and vibration FG beams under thermal loads [17]. Thom and Kien studied the free vibrations of two-directional FG beams in thermal surroundings [18].

With rapid progression in structure technology, the latest achievements in the field of FG materials can be the porosity of these materials. Therefore, the effect of porosity is of special importance. These porous structures have interesting mechanical attributes like excessive rigidity related to very low determined weight. So far, some studies have been done about the vibrational behavior of this porous structure. Linear and nonlinear studies on vibrations of FG permeable beams depending on an elastic substrate were investigated by Wattanasakulpong and Ungbhakorn [19]. Ebrahimi and Jafari studied the temperature impact on vibrations of FG beams with two porosity types and Timoshenko's theory [20]. Ait Atmane et al. checked out the thickness and permeable effect on FG beam's mechanical responses on elastic substrates [21]. Heshmati and Daneshmand investigated the vibration analysis of nonuniform porous beams with porosity distribution in FG state [22]. Akbaş et al. presented a dynamic analysis of thick beams with porous layers in FG and viscoelastic support [23].

Often, numerical approximation methods have to be sought to solve vibration problems due to the complexity of the problems. Classical techniques such as finite element and finite difference methods are well developed and well known. These methods can provide very accurate results by using a large number of grid points; thus, they are computationally expensive. In a large number of cases, only a limited number of frequencies and mode shapes or a dynamic response at only a limited number of points needs to be found. Also, due to the difficulties with the shear deformation theory of third order, to solve the equations of governing, powerful techniques are required; therefore, the differential quadrature method (DQM) was used in this research. The DQM discretizes any derivative at a point by a weighted linear sum of functional values at its neighboring points. In the generalized differential quadrature method (GDQM), by considering the cosine division function, the number of nodes at the border increases, the calculations decrease, and the speed of convergence to the answers increases. For the free vibration analysis of FG panels, shells, plates, and beams, this method was applied by Bert and Malik [24], Farid et al. [25], Malekzadeh and Heydarpour [26], Ersoy et al. [27], Wang et al. [28], Wang et al. [29], Wang et al. [30], Al-Furjan et al. [31], Al-Furjan et al. [32], Shariati et al. [33], Huang et al. [34], Al-Furjan et al. [35], Huang et al. [34], and Al-Furjan et al. [36]. Zahedinejad investigated the free vibrations of FG beams depending on a two-parameter elastic foundation in a temperature-rise environment with DQM [37].

The novelty of this paper is the simultaneous FG porous beam analysis using the theory of third-order shear deformation on the elastic substrate in the temperature-dependent environment by GDQM. The motivation of this research is a thermomechanical analysis of thick FG porous structures under different thermal loads and also to evaluate the accuracy of GDQM. For example, hot section blades of gas turbine and plasma-facing components in divertor of a nuclear reactor are exposed to thermal loads. In this research, analysis of the free vibration FG porous beams with uniform porosity distribution is studied according to the theory of third-order shear deformation. The porosity distribution is considered through the beam thickness direction. Additionally, the effect of thermal loads and elastic substrate impact was considered on the frequency parameters. Hamilton's principle is used to obtain boundary conditions and equations of motion, and the GDQM was used to solve them. The materials attributes are a function of temperature and differ over the beam thickness direction with the distribution of power law. The behavioral convergence method was applied and the accuracy of the consequences was investigated with other solutions due to the articles. This research considered the geometric parameters impact, various temperature distributions and elastic substrate stiffness coefficients, and porosity volume fraction, according to FG porous beam natural frequencies.

\section{Kinematics}

Figure 1 showed uniform porosity of FG porous beam, width $b$, length $L$, and height $h$ depending on an elastic substrate. The displacement field is selected through the beam theories of third-order shear deformation with the following assumptions: (1) Shear components and bending are components of the transverse and axial displacements. (2) The bending component of the classical beam theory and the axial displacement in this theory are similar. (3) Shear axial displacement and the third-degree variation of shear strain 


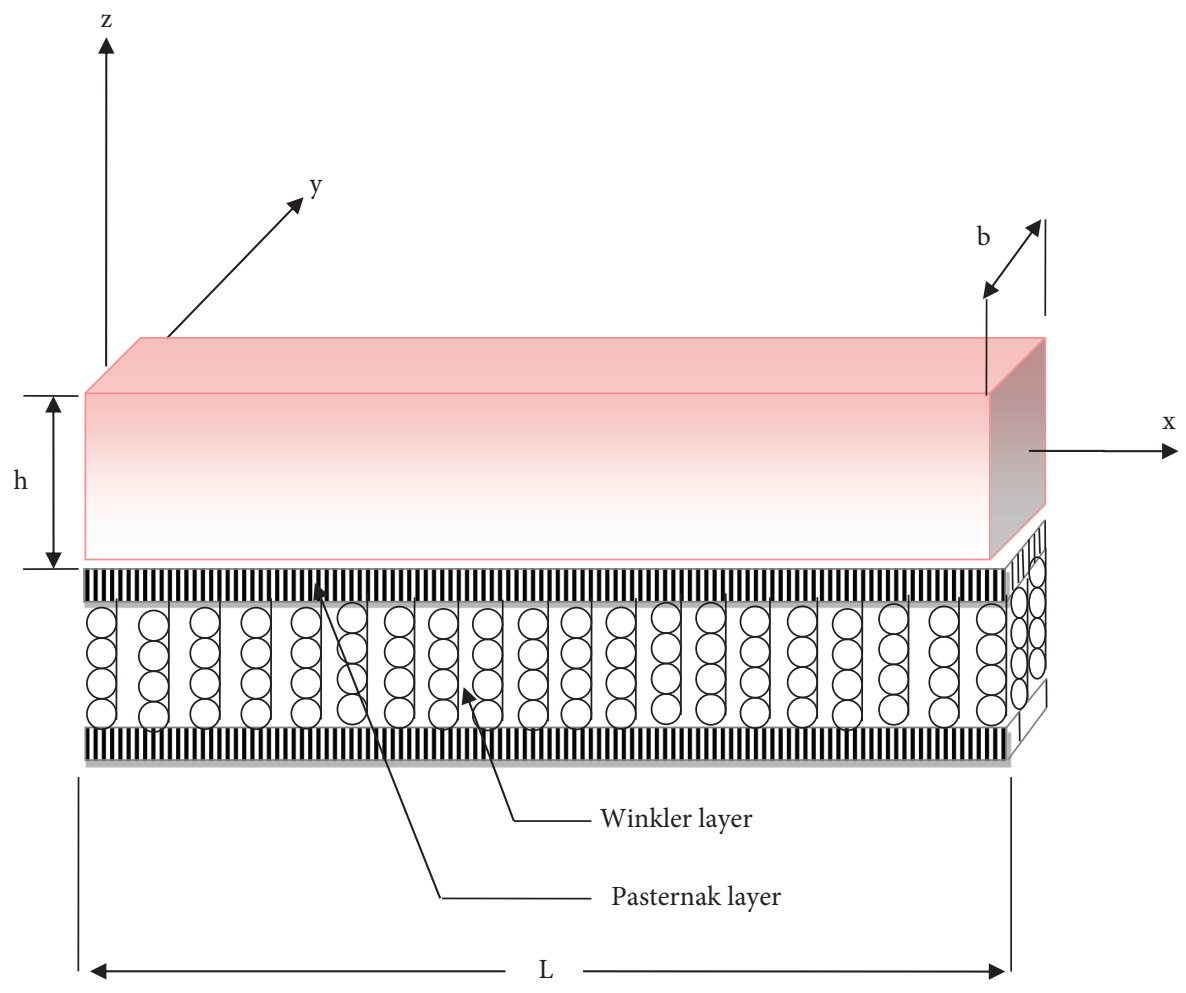

FIGURE 1: FG porous beam schematic depending on an elastic substrate.

in the beam depth direction are different and the shear stress in upper and lower beam planes is zero.

According to these assumptions [38], the field of the displacement is

$$
\begin{aligned}
& u_{1}(x, z, t)=u(x, t)-z \frac{\partial w_{b}}{\partial x}-f(z) \frac{\partial w_{s}}{\partial x}, \\
& u_{2}(x, z, t)=0, \\
& u_{3}(x, z, t)=w_{b}(x, t)+w_{s}(x, t),
\end{aligned}
$$

where $u_{i}(i=1,2,3), w_{s}$, and $w_{b}$ represent the axial displacement, shear, and bending components of horizontal displacement on the beam midpoint. The shear stress and the horizontal shear strain distribution at the beam depth satisfy the boundary conditions of stress-free up and low beam planes represented by the shape function $f(z)$. According to Reddy's shear deformation theory [39], this function can be shown as

$$
f(z)=\frac{4 z^{3}}{3 h^{2}} .
$$

The present field of displacement and Reddy's theory are different from each other. Two components of the horizontal displacement are the displacements due to bending and shear. Strains can be defined as

$$
\begin{aligned}
& \varepsilon_{x x}=\frac{\partial u}{\partial x}-z \frac{\partial^{2} w_{b}}{\partial x^{2}}-f(z) \frac{\partial^{2} w_{s}}{\partial x^{2}}, \\
& \gamma_{x z}=\left(1-\frac{d f(z)}{d z}\right) \frac{\partial w_{s}}{\partial x} \equiv g(z) \frac{\partial w_{s}}{\partial x} .
\end{aligned}
$$

\section{FG Porous Materials Properties}

The beam material composition changes from the metal-rich lowest surface $(z=-h / 2)$ to the ceramic-rich upper surface $(z=h / 2)$, following a simple power law relating to the volume fractions of the constituents; that is,

$$
\begin{aligned}
V_{c} & =\left(\frac{1}{2}+\frac{z}{h}\right)^{p}, \\
V_{m} & =1-V_{c},
\end{aligned}
$$

where $-h / 2 \leq z \leq h / 2$ and $p$ is the material index of power law, which is greater than or equal to zero. The case where $p$ is equal to zero shows a completely ceramic beam, while the approaching infinity shows an almost fully metallic beam. Parameters $V_{m}$ and $V_{c}$ denote the fractions of the metal and ceramic volume. The main attributes $P_{e f f}$, such as Poisson's ratio $v$, Young's modulus $E$, and thermal expansion coefficient, are specified as 


$$
P_{e f f}(z, T)=\left(P_{c}(T)-P_{m}(T)\right) V_{c}+P_{m}(T)-\left(P_{c}(T)+P_{m}(T)\right) \frac{a}{2},
$$

where $a$ is the porosity coefficient.

FG materials are often applied in high-temperature surroundings with unavoidable changes in material attributes. Here position and temperature are important factors in the FG beam material attributes, so accurately predicting the structural response should be considered in accordance with the temperature. Material properties are stated as environmental nonlinear function at temperature $T(K)$ as

$$
P(T)=P_{0}\left(P_{-1} T^{-1}+1+P_{1} T+P_{2} T^{2}+P_{3} T^{3}\right),
$$

whereas $T(z)=T_{0}+\Delta T(z), T_{0}=300 \mathrm{~K}$, and $P_{0}, P_{-1}, P_{1}, P_{2}$, and $P_{3}$ are unique temperature-dependent coefficients for the materials of constituent. It is assumed that, in the thickness direction, the temperature varies with upper and lower surfaces temperatures being known. Due to this case, to calculate the temperature function along the thickness direction, the following steady-state heat transfer equation can be solved:

$$
-\frac{d}{d z}\left[k \frac{d T}{d z}\right]=0
$$

Imposing the boundary conditions solved this equation: $T=T_{c}$ in $z=h / 2$ and $T=T_{m}$ in $z=-h / 2$.

The equation solution in [40] is as follows:

$$
T(z)=T_{c}-\frac{T_{c}-T_{m}}{\int_{-h / 2}^{h / 2} d z / k(z, T)} \int_{-h / 2}^{z} \frac{d z}{k(z, T)},
$$

where $k(z, T)$ is thermal conductivity.

\section{Equations of Governing}

Hamilton's principle is determined for the FG beam equations of the motion.

$$
\int_{t_{1}}^{t_{2}}\left(\delta K-\delta U-\delta V_{e f}\right) d t=0
$$

where $t, t_{1}$, and $t_{2}$, respectively, are the time and the initial and end times; $\delta K, \delta U$, and $\delta V_{e f}$ are the kinetic and the total strain energy variations and the potential energy of the elastic substrate variations. The total beam strain energy can be shown as

$$
U=U_{d}+U_{T}
$$

where $U_{d}$ and $U_{T}$ are, respectively, the strain energy because of mechanical stresses and the initial stresses of the strain energy as a result of temperature rise. These strains are represented by the following equations [41]:

$$
\begin{aligned}
& U_{d}=\frac{1}{2} \int_{0}^{L} \int_{A}\left(\sigma_{x x} \varepsilon_{x x}+\sigma_{x z} \gamma_{x z}\right) d A \mathrm{~d} x, \\
& \sigma_{x x}=E(z, T) \varepsilon_{x x}, \\
& \sigma_{x z}=\frac{E(z, T)}{2(1+v(z, T))} \\
& U_{T}=\frac{1}{2} \int_{0}^{L} \int_{A}\left(\sigma_{x x}^{T} d_{x x}\right) d A \mathrm{~d} x, \\
& d_{x x}=\left(\frac{\partial u_{1}}{\partial x}\right)^{2}+\left(\frac{\partial u_{3}}{\partial x}\right)^{2} .
\end{aligned}
$$

The thermal stress in (12) is presented by

$$
\sigma_{x x}^{T}=-\frac{E(z, T) \alpha(z, T)}{1-v(z, T)} \Delta T(z)
$$

The potential energy and the kinetic energy in the elastic substrate can be given by

$$
\begin{aligned}
K & =\frac{1}{2} \int_{0}^{L} \int_{A} \rho(z)\left(\dot{u}_{1}^{2}+\dot{u}_{3}^{2}\right) d A \mathrm{~d} x, \\
V_{e f} & =\left.\frac{1}{2} \int_{0}^{L} \int_{0}^{b}\left[k_{w} u_{3}^{2}+k_{p}\left(\frac{\partial u_{3}}{\partial x}\right)^{2}\right]\right|_{z=0} d y d x,
\end{aligned}
$$

where the Winkler and shearing-layer elastic coefficients of the substrate are $k_{w}$ and $k_{p}$ depending on the soil and underlayer properties, like elastic modulus, Poisson's soil ratio, and the soil length. By replacing equations (10)-(16) in (9) and integrating by components according to space and time, the motion equations of FG beam are considered as

$$
\begin{gathered}
\delta u: I_{0} \ddot{u}-I_{1} \frac{\partial \ddot{w}_{b}}{\partial x}-J_{1} \frac{\partial \ddot{w}_{s}}{\partial x}=\frac{\partial N}{\partial x}+\frac{\partial N^{T}}{\partial x} \\
\delta w_{b}: I_{0}\left(\ddot{w}_{b}+\ddot{w}_{s}\right)+I_{1} \frac{\partial \ddot{u}}{\partial x}-I_{2} \frac{\partial^{2} \ddot{w}_{b}}{\partial x^{2}}-J_{2} \frac{\partial^{2} \ddot{w}_{s}}{\partial x^{2}}=\frac{\partial^{2} M_{b}}{\partial x^{2}} \\
+\frac{\partial^{2} M_{b}^{T}}{\partial x^{2}}+\left(A^{T}+k_{p}\right)\left(\frac{\partial^{2} w_{b}}{\partial x^{2}}+\frac{\partial^{2} w_{s}}{\partial x^{2}}\right)-k_{w}\left(w_{b}+w_{s}\right),
\end{gathered}
$$

$$
\begin{aligned}
\delta w_{s}: & I_{0}\left(\ddot{w}_{b}+\ddot{w}_{s}\right)+J_{1} \frac{\partial \ddot{u}}{\partial x}-J_{2} \frac{\partial^{2} \ddot{w}_{b}}{\partial x^{2}}-K_{2} \frac{\partial^{2} \ddot{w}_{s}}{\partial x^{2}}=\frac{\partial^{2} M_{s}}{\partial x^{2}} \\
+ & \frac{\partial^{2} M_{s}^{T}}{\partial x^{2}}+\left(A^{T}+k_{p}\right)\left(\frac{\partial^{2} w_{b}}{\partial x^{2}}+\frac{\partial^{2} w_{s}}{\partial x^{2}}\right)+\frac{\partial Q}{\partial x}-k_{w}\left(w_{b}+w_{s}\right),
\end{aligned}
$$

Where $N, N^{T} ، M_{b} ، M_{b}^{T} ، M_{s} ، M_{s}^{T}$, and $Q$ parameters are defined as 


$$
\begin{aligned}
N & =A \frac{\partial u}{\partial x}-B \frac{\partial^{2} w_{b}}{\partial x^{2}}-B_{s} \frac{\partial^{2} w_{s}}{\partial x^{2}} \\
N^{T} & =A^{T} \frac{\partial u}{\partial x}-B^{T} \frac{\partial^{2} w_{b}}{\partial x^{2}}-B_{s}^{T} \frac{\partial^{2} w_{s}}{\partial x^{2}} \\
M_{b} & =B \frac{\partial u}{\partial x}-D \frac{\partial^{2} w_{b}}{\partial x^{2}}-D_{s} \frac{\partial^{2} w_{s}}{\partial x^{2}} \\
M_{b}^{T} & =B^{T} \frac{\partial u}{\partial x}-D^{T} \frac{\partial^{2} w_{b}}{\partial x^{2}}-D_{s}^{T} \frac{\partial^{2} w_{s}}{\partial x^{2}} \\
M_{s} & =B_{s} \frac{\partial u}{\partial x}-D_{s} \frac{\partial^{2} w_{b}}{\partial x^{2}}-H_{s} \frac{\partial^{2} w_{s}}{\partial x^{2}} \\
M_{s}^{T} & =B_{s}^{T} \frac{\partial u}{\partial x}-D_{s}^{T} \frac{\partial^{2} w_{b}}{\partial x^{2}}-H_{s}^{T} \frac{\partial^{2} w_{s}}{\partial x^{2}} \\
Q & =A_{s} \frac{\partial w_{s}}{\partial x} .
\end{aligned}
$$

The estimations of coefficients are as follows:

$$
\begin{aligned}
\left(I_{0}, I_{1}, J_{1}, I_{2}, J_{2}, K_{2}\right) & =\int_{A} \rho(z)\left(1, z, f(z), z^{2}, z f(z), f^{2}(z)\right) d A \\
\left(A, B, B_{s}, D, D_{s}, H_{s}\right) & =\int_{A} E(z, T)\left(1, z, f(z), z^{2}, z f(z), f^{2}(z)\right) d A, \\
A_{s} & =\int_{A} \frac{E(z, T)}{2(1+v(z, T))} g^{2}(z) d A \\
\left(A^{T}, B^{T}, B_{s}^{T}, D^{T}, D_{s}^{T}, H_{s}^{T}\right) & =\int_{A} \sigma_{x x}^{T}\left(1, z, f(z), z^{2}, z f(z), f^{2}(z)\right) d A .
\end{aligned}
$$

The motion equations of the substation parts are estimated by replacing relations (20)-(26) with (17)-(19) as follows:

$$
\delta u: I_{0} \ddot{u}-I_{1} \frac{\partial \ddot{w}_{b}}{\partial x}-J_{1} \frac{\partial \ddot{w}_{s}}{\partial x}=\left(A+A^{T}\right) \frac{\partial^{2} u}{\partial x^{2}}-\left(B+B^{T}\right) \frac{\partial^{3} w_{b}}{\partial x^{3}}-\left(B_{s}+B_{s}^{T}\right) \frac{\partial^{3} w_{s}}{\partial x^{3}}
$$

$$
\begin{aligned}
& \delta w_{b}: I_{0}\left(\ddot{w}_{b}+\ddot{w}_{s}\right)+I_{1} \frac{\partial \ddot{u}}{\partial x}-I_{2} \frac{\partial^{2} \ddot{w}_{b}}{\partial x^{2}}-J_{2} \frac{\partial^{2} \ddot{w}_{s}}{\partial x^{2}}=\left(B+B^{T}\right) \frac{\partial^{3} u}{\partial x^{3}}-\left(D+D^{T}\right) \frac{\partial^{4} w_{b}}{\partial x^{4}}-\left(D_{s}+D_{s}^{T}\right) \frac{\partial^{4} w_{s}}{\partial x^{4}}+\left(A^{T}+k_{p}\right)\left(\frac{\partial^{2} w_{b}}{\partial x^{2}}+\frac{\partial^{2} w_{s}}{\partial x^{2}}\right) \\
& \quad-k_{w}\left(w_{b}+w_{s}\right),
\end{aligned}
$$




$$
\begin{aligned}
& \delta w_{s}: I_{0}\left(\ddot{w}_{b}+\ddot{w}_{s}\right)+J_{1} \frac{\partial \ddot{u}}{\partial x}-J_{2} \frac{\partial^{2} \ddot{w}_{b}}{\partial x^{2}}-K_{2} \frac{\partial^{2} \ddot{w}_{s}}{\partial x^{2}}=\left(B_{s}+B_{s}^{T}\right) \frac{\partial^{3} u}{\partial x^{3}}-\left(D_{s}+D_{s}^{T}\right) \frac{\partial^{4} w_{b}}{\partial x^{4}}-\left(H_{s}+H_{s}^{T}\right) \frac{\partial^{4} w_{s}}{\partial x^{4}} \\
& +\left(A^{T}+k_{p}\right)\left(\frac{\partial^{2} w_{b}}{\partial x^{2}}+\frac{\partial^{2} w_{s}}{\partial x^{2}}\right)+A_{s} \frac{\partial^{2} w_{s}}{\partial x^{2}}-k_{w}\left(w_{b}+w_{s}\right) .
\end{aligned}
$$

\section{Conditions of Boundary}

These parameters are determined due to the FG beam conditions of the boundary:

$$
\begin{aligned}
& \left(N+N^{T}\right)=0 \text { or } u=0, \\
& Q_{b} \equiv \frac{\partial M_{b}}{\partial x}+\frac{\partial M_{b}^{T}}{\partial x}+A^{T}\left(\frac{\partial w_{b}}{\partial x}+\frac{\partial w_{s}}{\partial x}\right)-I_{1} \ddot{u}+I_{2} \frac{\partial \ddot{w}_{b}}{\partial x} \\
& +J_{2} \frac{\partial \ddot{w}_{s}}{\partial x}=0 \text { or } w_{b} \\
& =0 \text {, } \\
& Q_{s} \equiv \frac{\partial M_{s}}{\partial x}+\frac{\partial M_{s}^{T}}{\partial x}+A^{T}\left(\frac{\partial w_{b}}{\partial x}+\frac{\partial w_{s}}{\partial x}\right)+Q-J_{1} \ddot{u}+J_{2} \frac{\partial \ddot{w}_{b}}{\partial x} \\
& +K_{2} \frac{\partial \ddot{w}_{s}}{\partial x}=0 \text { or } w_{s} \\
& =0 \text {, } \\
& \begin{array}{r}
\left(M_{b}+M_{b}^{T}\right)=0 \text { or } \frac{\partial w_{b}}{\partial x} \\
=0 \\
\left(M_{s}+M_{s}^{T}\right)=0 \text { or } \frac{\partial w_{s}}{\partial x} \\
=0
\end{array}
\end{aligned}
$$

$x=0$ and $x=L$ are different conditions which can be obtained by combining the conditions in (30)-(35). The simple soft support conditions of boundary in this research are examined as follows: 


$$
\begin{aligned}
& \left(A+A^{T}\right) \frac{\partial u}{\partial x}-\left(B+B^{T}\right) \frac{\partial^{2} w_{b}}{\partial x^{2}}-\left(B_{s}+B_{s}^{T}\right) \frac{\partial^{2} w_{s}}{\partial x^{2}}=0 \text { or }\left(N+N^{T}\right)=0 \\
& \left(B+B^{T}\right) \frac{\partial u}{\partial x}-\left(D+D^{T}\right) \frac{\partial^{2} w_{b}}{\partial x^{2}}-\left(D_{s}+D_{s}^{T}\right) \frac{\partial^{2} w_{s}}{\partial x^{2}}=0 \text { or }\left(M_{b}+M_{b}^{T}\right)=0 \\
& \left(B_{s}+B_{s}^{T}\right) \frac{\partial u}{\partial x}-\left(D_{s}+D_{s}^{T}\right) \frac{\partial^{2} w_{b}}{\partial x^{2}}-\left(H_{s}+H_{s}^{T}\right) \frac{\partial^{2} w_{s}}{\partial x^{2}}=0 \text { or }\left(M_{s}+M_{s}^{T}\right)=0, \\
& \quad w_{b}=0, w_{s}=0 . \\
& M\left(x_{i}\right)=\prod_{j=1}^{N_{x}}\left(x_{i}-x_{j}\right) .
\end{aligned}
$$

For substitution components, these answers apply to analyze free vibrations:

$$
\begin{aligned}
u(x, t) & =\bar{u}(x) e^{I \omega t}, \\
w_{b}(x, t) & =\bar{w}_{b}(x) e^{I \omega t}, \\
w_{s}(x, t) & =\bar{w}_{s}(x) e^{I \omega t},
\end{aligned}
$$

where $I=\sqrt{-1}$ and $\omega$ is natural frequency.

\section{Differential Quadrature Separation}

The DQ separation rules based on Gauss-Lobatto-Chebyshev sampling points known as Generalized Differential Quadrature (GDQ) are attained to transfer the constitutive equations and related boundary conditions into algebraic equations [24].

$$
x_{i}=\frac{1}{2}\left\{1-\cos \left(\frac{i-1}{N_{x}-1}\right) \pi\right\}, \quad i=1,2, \ldots, N_{x}-1 .
$$

The $n$ th-order partial derivative of $\mathrm{f}(\mathrm{x})$ with respect to $x$ at the discrete point $x_{i}$ is

$$
f_{x}^{(n)}\left(x_{i}\right)=\sum_{i=1}^{N_{x}} C_{i j}^{(n)} f\left(x_{i}\right)
$$

where $N_{x}$ is the number of the differential quadrature separation items in the direction of length. $C_{i j}^{(n)}$ are weighting coefficients associated with the $n$ th-order partial derivative of $f(x)$ with respect to $x$ at the discrete point $x_{i}$. The first one is

$$
C_{i j}^{1}=\frac{M\left(x_{i}\right)}{\left(x_{i}-x_{j}\right) M\left(x_{j}\right)},
$$

where
The weighting coefficients of higher-order derivatives can be obtained through the following recurrence relation: $C_{i j}^{(n)}=n\left(C_{i j}^{(n-1)} C_{i j}^{1}-\frac{C_{i j}^{(n-1)}}{\left(x_{i}-x_{j}\right)}\right) \quad i, j=1,2, \ldots N_{x}$,

$C_{i j}^{(n)}=-\sum_{j=1 j \neq i}^{N_{x}} C_{i j}^{n} \quad n=1,2, \ldots N_{x}-1$.

Based on this method, the partial derivatives of a function can be given as

$$
\begin{aligned}
& \left.\frac{\partial f(x, t)}{\partial x}\right|_{x=x_{i}}=\sum_{j=1}^{N_{x}} A_{i j} f\left(x_{j}, t\right) i=1,2, \ldots, N_{x}, \\
& \left.\frac{\partial^{2} f(x, t)}{\partial x^{2}}\right|_{x=x_{i}}=\sum_{j=1}^{N_{x}} B_{i j} f\left(x_{j}, t\right), \\
& \left.\frac{\partial^{3} f(x, t)}{\partial x^{3}}\right|_{x=x_{i}}=\sum_{j=1}^{N_{x}} C_{i j} f\left(x_{j}, t\right), \\
& \left.\frac{\partial^{4} f(x, t)}{\partial x^{4}}\right|_{x=x_{i}}=\sum_{j=1}^{N_{x}} D_{i j} f\left(x_{j}, t\right),
\end{aligned}
$$

where $A_{i j}, B_{i j}, C_{i j}$, and $D_{i j}$ are the first-, second-, third-, and fourth-order weighting coefficients of the DQM, respectively.

The conditions of boundary and the motion equations are converted to DQM as the equations related algebra. The 
differential equations of governing and conditions of boundary are considered as separation use for derivatives (24) and relations (28)-(30) and (36) and DQM as follows:

$$
\begin{aligned}
& \left(A+A^{T}\right) \sum_{j=1}^{N_{x}} B_{i j} \bar{u}_{j}-\left(B+B^{T}\right) \sum_{j=1}^{N_{x}} C_{i j} \bar{w}_{b j}-\left(B_{s}+B_{s}^{T}\right) \sum_{j=1}^{N_{x}} C_{i j} \bar{w}_{s j}+\omega^{2}\left(I_{0} \bar{u}_{i}-I_{1} \sum_{j=1}^{N_{x}} A_{i j} \bar{w}_{b j}-J_{1} \sum_{j=1}^{N_{x}} A_{i j} \bar{w}_{s j}\right)=0, \\
& \left(B+B^{T}\right) \sum_{j=1}^{N_{x}} C_{i j} \bar{u}_{j}-\left(D+D^{T}\right) \sum_{j=1}^{N_{x}} D_{i j} \bar{w}_{b j}-\left(D_{s}+D_{s}^{T}\right) \sum_{j=1}^{N_{x}} D_{i j} \bar{w}_{s j}+\left(A^{T}+k_{g}\right)\left(\sum_{j=1}^{N_{x}} B_{i j}\left(\bar{w}_{b j}+\bar{w}_{s j}\right)\right)-k_{w}\left(\bar{w}_{b i}+\bar{w}_{s i}\right) \\
& +\omega^{2}\left(I_{0}\left(\bar{w}_{b i}+\bar{w}_{s i}\right)+I_{1} \sum_{j=1}^{N_{x}} A_{i j} \bar{u}_{j}-I_{2} \sum_{j=1}^{N_{x}} B_{i j} \bar{w}_{b j}-J_{2} \sum_{j=1}^{N_{x}} B_{i j} \bar{w}_{s j}\right)=0 \\
& \left(B_{s}+B_{s}^{T}\right) \sum_{j=1}^{N_{x}} C_{i j} \bar{u}_{j}-\left(D_{s}+D_{s}^{T}\right) \sum_{j=1}^{N_{x}} D_{i j} \bar{w}_{b j}-\left(H_{s}+H_{s}^{T}\right) \sum_{j=1}^{N_{x}} D_{i j} \bar{w}_{s j}+\left(A^{T}+k_{g}\right)\left(\sum_{j=1}^{N_{x}} B_{i j}\left(\bar{w}_{b j}+\bar{w}_{s j}\right)\right)-k_{w}\left(\bar{w}_{b i}+\bar{w}_{s i}\right) \\
& +A_{s} \sum_{j=1}^{N_{x}} B_{i j} \bar{w}_{s j}+\omega^{2}\left(I_{0}\left(\bar{w}_{b i}+\bar{w}_{s i}\right)+J_{1} \sum_{j=1}^{N_{x}} A_{i j} \bar{u}_{j}-J_{2} \sum_{j=1}^{N_{x}} B_{i j} \bar{w}_{b j}-K_{2} \sum_{j=1}^{N_{x}} B_{i j} \bar{w}_{s j}\right)=0, \\
& \left(A+A^{T}\right) \sum_{j=1}^{N_{x}} A_{i j} \bar{u}_{j}-\left(B+B^{T}\right) \sum_{j=1}^{N_{x}} B_{i j} \bar{w}_{b j}-\left(B_{s}+B_{s}^{T}\right) \sum_{j=1}^{N_{x}} B_{i j} \bar{w}_{s j}=0, \\
& \left(B+B^{T}\right) \sum_{j=1}^{N_{x}} A_{i j} \bar{u}_{j}-\left(D+D^{T}\right) \sum_{j=1}^{N_{x}} B_{i j} \bar{w}_{b j}-\left(D_{s}+D_{s}^{T}\right) \sum_{j=1}^{N_{x}} B_{i j} \bar{w}_{s j}=0, \\
& \left(B_{s}+B_{s}^{T}\right) \sum_{j=1}^{N_{x}} A_{i j} \bar{u}_{j}-\left(D_{s}+D_{s}^{T}\right) \sum_{j=1}^{N_{x}} B_{i j} \bar{w}_{b j}-\left(H_{s}+H_{s}^{T}\right) \sum_{j=1}^{N_{x}} B_{i j} \bar{w}_{s j}=0, \\
& \bar{w}_{b i}=0, \bar{w}_{s i}=0 \text {. }
\end{aligned}
$$

Boundary conditions based on this method are written in relation (45).

The boundary degrees and domain of freedom separate parts of the freedom degrees for obtaining the eigenvalue system of equations as

$$
\{d\}=\left\{\begin{array}{c}
\{\bar{u}\}, \\
\left\{\overline{w_{b}}\right\}, \\
\left\{\overline{w_{s}}\right\},
\end{array}\right\}_{\text {domain }}, \quad\{b\}=\left\{\begin{array}{c}
\{\bar{u}\}, \\
\left\{\overline{w_{b}}\right\}, \\
\left\{\overline{w_{s}}\right\},
\end{array}\right\}_{\text {boundary }} .
$$

In the matrix form, using (46), the motion equations separated form can be arranged differently as

$$
\left[S_{d b}\right]\{b\}+\left[S_{d d}\right]\{d\}-\omega_{i}^{2}[M]\{d\}=0 .
$$

$[M]$ is the mass matrix where $\left[S_{d b}\right]$ and $\left[S_{d d}\right]$ are the rigid matrices. Similarly, the separated form condition of the boundary is

$$
\left[S_{b b}\right]\{b\}+\left[S_{b d}\right]\{d\}=0 .
$$

The rigid matrices are $\left[S_{b b}\right]$ and $\left[S_{b d}\right]$. For removing the freedom boundary degree $\{b\}$ from (47), (48) is applied resulting in

$$
\left([S]-\omega_{i}^{2}[M]\right)\{d\}=0,
$$

where $[S]=\left[S_{d d}\right]-\left[S_{d b}\right]\left[S_{b b}\right]^{-1}\left[S_{b d}\right]$. To find the natural frequencies, the former eigenvalue equation can be solved.

\section{Results and Discussion}

First, the method convergence is considered for simply supported conditions of boundary. The conclusion accuracy is confirmed by comparing other available solutions. A beam containing aluminum $(\mathrm{Al})$ and alumina $\left(\mathrm{Al}_{2} \mathrm{O}_{3}\right)$ is considered for temperature-independent states. Table 1 shows the FG material characteristics.

A beam concluding stainless steel (SUS304) and silicon nitride $\left(\mathrm{Si}_{3} \mathrm{~N}_{4}\right)$ is estimated for the temperature-dependent cases. In Table 2, the temperature-dependent material attributes for some metals and ceramics are listed, according to the data given in [40].

The natural frequency of nondimensional $\left(\lambda_{n}\right)$ are explained as

$$
\lambda_{n}=\frac{\omega_{n} L^{2}}{h} \sqrt{\frac{\rho_{m}}{E_{m}}} .
$$


TABle 1: Properties of alumina and aluminum.

\begin{tabular}{lcc}
\hline Properties & Metal $(\mathrm{Al})$ & $\mathrm{Ceramic}_{2}\left(\mathrm{Al}_{2} \mathrm{O}_{3}\right)$ \\
\hline$E(\mathrm{GPa})$ & 70 & 38 \\
$v$ & 0.3 & 0.3 \\
$\rho\left(\mathrm{kg} / \mathrm{m}^{3}\right)$ & 2702 & 3960 \\
\hline
\end{tabular}

TABle 2: The temperature-dependent coefficients in metals and ceramics.

\begin{tabular}{|c|c|c|c|c|c|c|}
\hline Material & Properties & $P_{0}$ & $P_{-1}$ & $P_{1}$ & $P_{2}$ & $P_{3}$ \\
\hline \multirow{5}{*}{$\mathrm{Si}_{3} \mathrm{~N}_{4}$} & $E(\mathrm{~Pa})$ & $348.43 e+9$ & 0 & $-3.070 e-4$ & $2.160 e-7$ & $-8.946 e-11$ \\
\hline & $\alpha(1 / K)$ & $5.8723 e-6$ & 0 & $9.095 e-4$ & 0 & 0 \\
\hline & $k(w / m K)$ & 13.723 & 0 & $-1.032 e-3$ & $5.466 e-7$ & $7.876 e-11$ \\
\hline & & 0.24 & 0 & 0 & 0 & 0 \\
\hline & $\rho\left(\mathrm{kg} / \mathrm{m}^{3}\right)$ & 2370 & 0 & 0 & 0 & 0 \\
\hline \multirow{5}{*}{ SUS304 } & $E(\mathrm{~Pa})$ & $201.04 e+9$ & 0 & $3.079 e-4$ & $-6.534 e-7$ & 0 \\
\hline & $\alpha(1 / K)$ & $12.330 e-6$ & 0 & $8.086 e-4$ & 0 & 0 \\
\hline & $k(w / m K)$ & 15.379 & 0 & $-1.264 e-3$ & $2.092 e-6$ & $-7.223 e-10$ \\
\hline & $v$ & 0.3262 & 0 & $-2.002 e-4$ & $3.797 e-7$ & 0 \\
\hline & $\rho\left(\mathrm{kg} / \mathrm{m}^{3}\right)$ & 8166 & 0 & 0 & 0 & 0 \\
\hline
\end{tabular}

The metallic layer density and Young's modulus are $\rho_{m}$ and $E_{m}$. Parameter values at the reference temperature of $T_{0}=300 \mathrm{~K}$ are used for temperature-dependent FG beam. The dimensionless elastic substrate constants are defined as

$$
\begin{aligned}
& K_{w}=\frac{k_{w} L^{4}}{E_{0} I}, \\
& K_{P}=\frac{k_{P} L^{2}}{\pi^{2} E_{0} I} .
\end{aligned}
$$

Parameter $I$ is defined as

$$
I=\frac{b h^{3}}{12} \text {. }
$$

Here, the number of differential quadrature grid points along the length was investigated for frequency convergence. However, the elastic substrate and porosity effects were ignored. Table 3 presents the natural frequency converging for simply supported conditions. In this table, it is clear that the results converged with $N_{x}=29$.

In Table 4 the parameters of frequency were estimated and compared with those by Ebrahimi and Jafari [20] and Şimşek [9]. The good agreement was observed.

Further confirming the results obtained from the GDQM, Zahedinejad, in an article [37], investigated the isotropic beam frequencies depending on an elastic layer and in comparison with Matsunga [34]. The impacts of elastic substrate and slenderness ratio parameters are considered. The method accuracy was observed between the presented results in close agreement.

In Table 5, the first nondimensional frequency computed under the temperature-dependent environments with conditions of the simply supported boundary is compared with those by Ebrahimi and Jafari [20]. Here, three thermal states are considered: (1) uniform temperature rise (UTR),
TABLE 3: First three frequencies of nondimensional converging $(p=5)$.

\begin{tabular}{ccccccccc}
\hline \multirow{2}{*}{$L / h \quad n$} & \multicolumn{8}{c}{$(\mathrm{Nx})$ number of grid points } \\
& & 5 & 9 & 15 & 21 & 25 & 29 & 33 \\
\hline \multirow{3}{*}{5} & 1 & 2.995 & 3.373 & 3.392 & 3.396 & 3.398 & 3.399 & 3.399 \\
& 2 & 19.546 & 11.512 & 11.482 & 11.511 & 11.521 & 11.526 & 11.526 \\
& 3 & 35.921 & 19.789 & 19.788 & 19.787 & 19.786 & 19.785 & 19.785 \\
\hline \multirow{4}{*}{20} & 1 & 3.273 & 3.646 & 3.648 & 3.648 & 3.648 & 3.648 & 3.648 \\
& 2 & 78.673 & 14.558 & 14.364 & 14.369 & 14.370 & 14.372 & 14.372 \\
& 3 & 143.686 & 36.194 & 31.522 & 31.551 & 31.559 & 31.565 & 31.565 \\
\hline
\end{tabular}

(2) linear temperature rise (LTR), and (3) nonlinear temperature rise (NLTR). There is a good agreement between the two solutions. The validity of using the GDQM is confirmed because of the above consequences comparison and the good agreement of these results and other articles. In the following, the various factors' impacts on the first frequencies are investigated.

For considering the elastic substrates impact on FG beam nondimensional natural frequencies, studies were performed on both parameters of the elastic substrates. A beam with uniform porosity distribution applies a uniform thermal load. By canceling Pasternak's parameter, for porosity coefficient values, the dimensionless frequencies variation versus the Winkler's parameter can be figured in Figure 2. Also, by canceling Winkler's parameter for various porosity coefficients, these variations are plotted versus Pasternak's parameter in Figure 3. From these figures, for the porosity coefficient value, enhancing Winkler's and Pasternak's parameters causes the natural frequencies to increase. Because of enhancing both elastic substrate factors, the complete system stiffness increases, and therefore the dimensionless frequencies increase. The higher frequencies can be obtained by the larger porosity coefficient values. As 
TABLE 4: Comparing frequency of first nondimensional FG beam simply supported conditions $\left(T_{c}=T_{m}=300, a=0, K_{w}=K_{p}=0\right)$.

\begin{tabular}{|c|c|c|c|c|c|c|c|}
\hline \multirow{2}{*}{$L / h$} & \multirow{2}{*}{\multicolumn{2}{|c|}{ Source and solution method }} & \multicolumn{5}{|c|}{ Material power law index $(p)$} \\
\hline & & & 0 & 0.2 & 0.5 & 1 & 2 \\
\hline \multirow{3}{*}{5} & Ebrahimi & Navier solution & 5.152 & 4.808 & 4.410 & 3.990 & 3.626 \\
\hline & Şimşek & Lagrange's equations & 5.152 & 4.806 & 4.408 & 3.990 & 3.634 \\
\hline & Present & DQM & 5.149 & 4.804 & 4.407 & 3.988 & 3.624 \\
\hline \multirow{3}{*}{20} & Ebrahimi & Navier solution & 5.460 & 5.081 & 4.651 & 4.205 & 3.836 \\
\hline & Şimşek & Lagrange's equations & 5.460 & 5.082 & 4.651 & 4.205 & 3.836 \\
\hline & Present & DQM & 5.460 & 5.081 & 4.651 & 4.205 & 3.836 \\
\hline
\end{tabular}

TABLE 5: Comparison of the first nondimensional frequency for simply supported FG porous beam with various thermal loads and material power law index $(L / h=20)$.

\begin{tabular}{|c|c|c|c|c|c|c|c|c|c|}
\hline \multirow{2}{*}{$a$} & \multirow{2}{*}{ Thermal loads } & \multirow{2}{*}{ Reference } & \multicolumn{7}{|c|}{$(p)$ power law index } \\
\hline & & & 0 & 0.1 & 0.2 & 0.5 & 25 & 29 & 33 \\
\hline \multicolumn{10}{|c|}{$\Delta T=20$} \\
\hline \multirow{6}{*}{0} & \multirow{2}{*}{ UTR } & Ebrahimi & 6.303 & 5.558 & 5.072 & 4.278 & 3.727 & 3.331 & 3.014 \\
\hline & & Present & 6.301 & 5.556 & 5.071 & 4.276 & 3.726 & 3.330 & 3.014 \\
\hline & \multirow{2}{*}{ LTR } & Ebrahimi & 6.358 & 5.615 & 5.132 & 4.340 & 3.389 & 3.390 & 3.071 \\
\hline & & Present & 6.337 & 5.595 & 5.129 & 4.320 & 3.781 & 3.388 & 3.074 \\
\hline & \multirow{2}{*}{ NLTR } & Ebrahimi & 6.358 & 5.616 & 5.134 & 4.343 & 3.792 & 3.394 & 3.074 \\
\hline & & Present & 6.346 & 5.609 & 5.131 & 4.341 & 3.791 & 3.393 & 3.073 \\
\hline \multirow{6}{*}{0.1} & \multirow{2}{*}{ UTR } & Ebrahimi & 6.889 & 5.911 & 5.308 & 4.369 & 3.744 & 3.308 & 2.968 \\
\hline & & Present & 6.880 & 5.907 & 5.303 & 4.366 & 3.741 & 3.306 & 2.966 \\
\hline & \multirow{2}{*}{ LTR } & Ebrahimi & 6.937 & 5.962 & 5.361 & 4.424 & 3.779 & 3.361 & 3.020 \\
\hline & & Present & 6.929 & 5.958 & 5.358 & 4.420 & 3.796 & 3.359 & 3.018 \\
\hline & \multirow{2}{*}{ NLTR } & Ebrahimi & 6.937 & 5.963 & 5.363 & 4.427 & 3.803 & 3.365 & 3.022 \\
\hline & & Present & 6.930 & 5.957 & 5.359 & 4.423 & 3.799 & 3.362 & 3.021 \\
\hline \multirow{6}{*}{0.2} & \multirow{2}{*}{ UTR } & Ebrahimi & 7.824 & 6.418 & 5.627 & 4.478 & 3.758 & 3.274 & 2.908 \\
\hline & & Present & 7.821 & 6.416 & 5.625 & 4.477 & 3.757 & 3.274 & 2.908 \\
\hline & \multirow{2}{*}{ LTR } & Ebrahimi & 7.865 & 6.463 & 5.675 & 4.527 & 3.807 & 3.321 & 2.953 \\
\hline & & Present & 7.859 & 6.458 & 5.670 & 4.523 & 3.805 & 3.319 & 2.953 \\
\hline & \multirow{2}{*}{ NLTR } & Ebrahimi & 7.894 & 6.464 & 5.676 & 4.530 & 3.810 & 3.324 & 2.955 \\
\hline & & Present & 7.884 & 6.458 & 5.670 & 4.525 & 3.797 & 3.321 & 2.953 \\
\hline \multicolumn{10}{|c|}{$\Delta T=40$} \\
\hline \multirow{6}{*}{0} & \multirow{2}{*}{ UTR } & Ebrahimi & 6.033 & 5.292 & 4.810 & 4.022 & 3.476 & 3.084 & 2.772 \\
\hline & & Present & 6.029 & 5.289 & 4.808 & 4.021 & 3.475 & 3.084 & 2.772 \\
\hline & \multirow{2}{*}{ LTR } & Ebrahimi & 6.213 & 5.480 & 5.002 & 4.218 & 3.671 & 3.276 & 2.959 \\
\hline & & Present & 6.207 & 5.475 & 4.994 & 4.213 & 3.667 & 3.273 & 2.957 \\
\hline & \multirow{2}{*}{ NLTR } & Ebrahimi & 6.213 & 5.482 & 5.006 & 4.224 & 3.678 & 3.283 & 2.964 \\
\hline & & Present & 6.205 & 5.475 & 5.001 & 4.219 & 3.675 & 3.280 & 2.962 \\
\hline \multirow{6}{*}{0.1} & \multirow[b]{2}{*}{ UTR } & Ebrahimi & 6.641 & 5.671 & 5.073 & 4.140 & 3.521 & 3.090 & 2.755 \\
\hline & & Present & 6.638 & 5.669 & 5.070 & 4.137 & 3.519 & 3.088 & 2.753 \\
\hline & ITR & Ebrahimi & 6.801 & 5.838 & 5.243 & 4.314 & 3.695 & 3.260 & 2.920 \\
\hline & LIK & Present & 6.792 & 5.830 & 5.236 & 4.308 & 3.689 & 3.256 & 2.917 \\
\hline & & Ebrahimi & 6.801 & 5.840 & 5.247 & 4.320 & 3.702 & 3.267 & 2.925 \\
\hline & NLIK & Present & 6.792 & 5.833 & 5.241 & 4.314 & 3.697 & 3.264 & 2.923 \\
\hline & & Ebrahimi & 7.595 & 6.602 & 5.418 & 4.277 & 3.563 & 3.084 & 2.723 \\
\hline & UTR & Present & 7.590 & 6.197 & 5.415 & 4.275 & 3.561 & 3.082 & 2.721 \\
\hline & & Ebrahimi & 7.736 & 6.349 & 5.568 & 4.430 & 3.715 & 3.232 & 2.867 \\
\hline 0.2 & LIK & Present & 7.728 & 6.334 & 5.564 & 4.426 & 3.711 & 3.229 & 2.865 \\
\hline & & Ebrahimi & 7.736 & 6.351 & 5.572 & 4.437 & 3.722 & 3.239 & 2.871 \\
\hline & NLIR & Present & 7.727 & 6.346 & 5.566 & 4.433 & 3.718 & 3.236 & 2.869 \\
\hline
\end{tabular}

shown in Figure 4, natural frequencies versus different temperature differences are in the range of 4 to 7 for different values of Winkler's parameter, and those are in the range of 25 to 40 for different values of Pasternak's parameter.
Pasternak's parameter has a greater effect on natural frequencies than Winkler's parameter; also, combining both elastic substrate factors caused higher frequencies. In other words, Pasternak's parameter and combining both elastic 


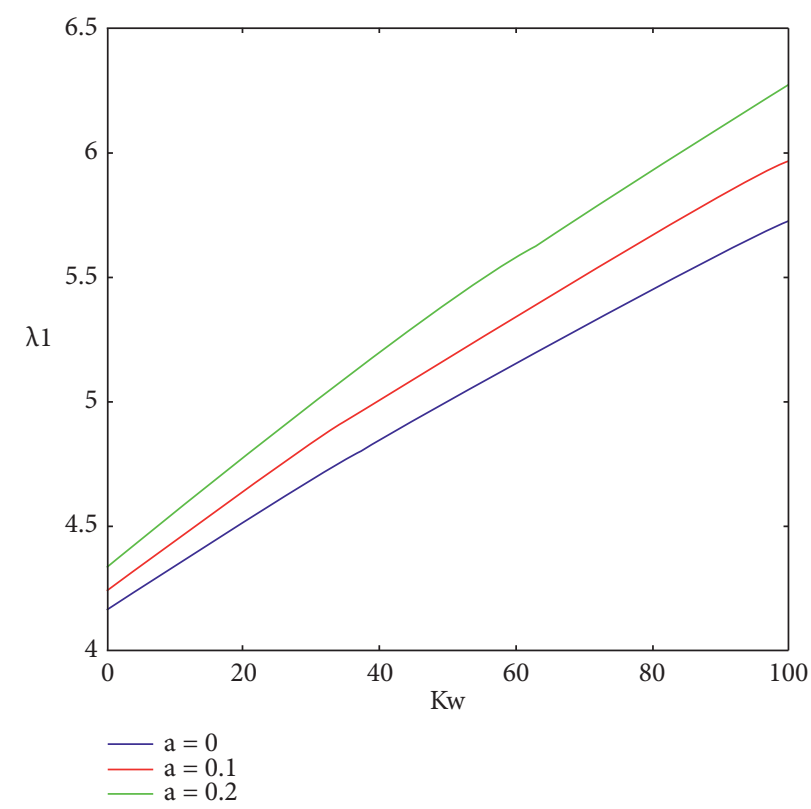

FIGURE 2: Winkler's parameters impact on the first nondimensional FG porous beam frequency with the simply supported condition. $p=0.5, \Delta T=100$, and $L / h=5$.

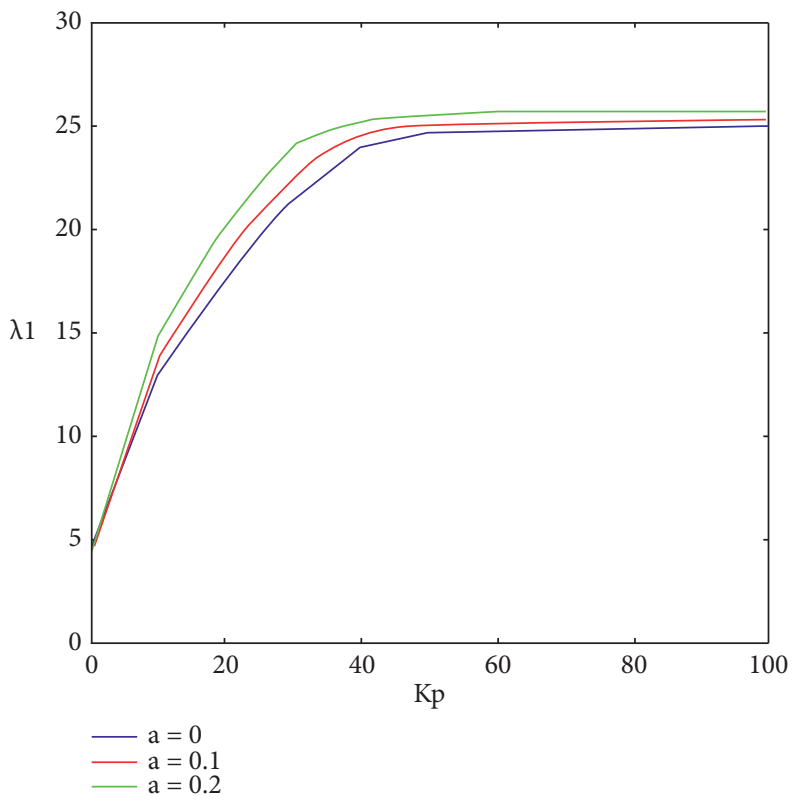

FIGURE 3: Pasternak's parameters impact on the first nondimensional FG porous beam frequency with the simply supported condition. $p=0.5, \Delta T=100$, and $L / h=5$.

substrate parameters increase the stiffness and thus increase the natural frequency.

Figure 5 shows the temperature impact on frequencies, the variation of nondimensional natural frequency versus temperature for different power law indexes, and a constant slenderness ratio. A uniform temperature rise is subjected by the beam with a uniform porosity distribution. For power law indexes smaller than one, first, the natural frequency decreases with increasing temperature and then further natural frequency increases with rising temperature. But, always for indexes of power law greater than one, decreasing the natural frequencies of the beam concurred with increasing temperature. In the case of porous beams, given the modulus of elasticity, density, coefficients of inertia, and other mechanical properties in addition to the observance of temperature and porosity, it can also be affected by the power law index. The natural frequency with increasing temperature depending on the value of the power law index and porosity coefficient has been down to a point, and, from there, with the predominance of the effects of the power law 

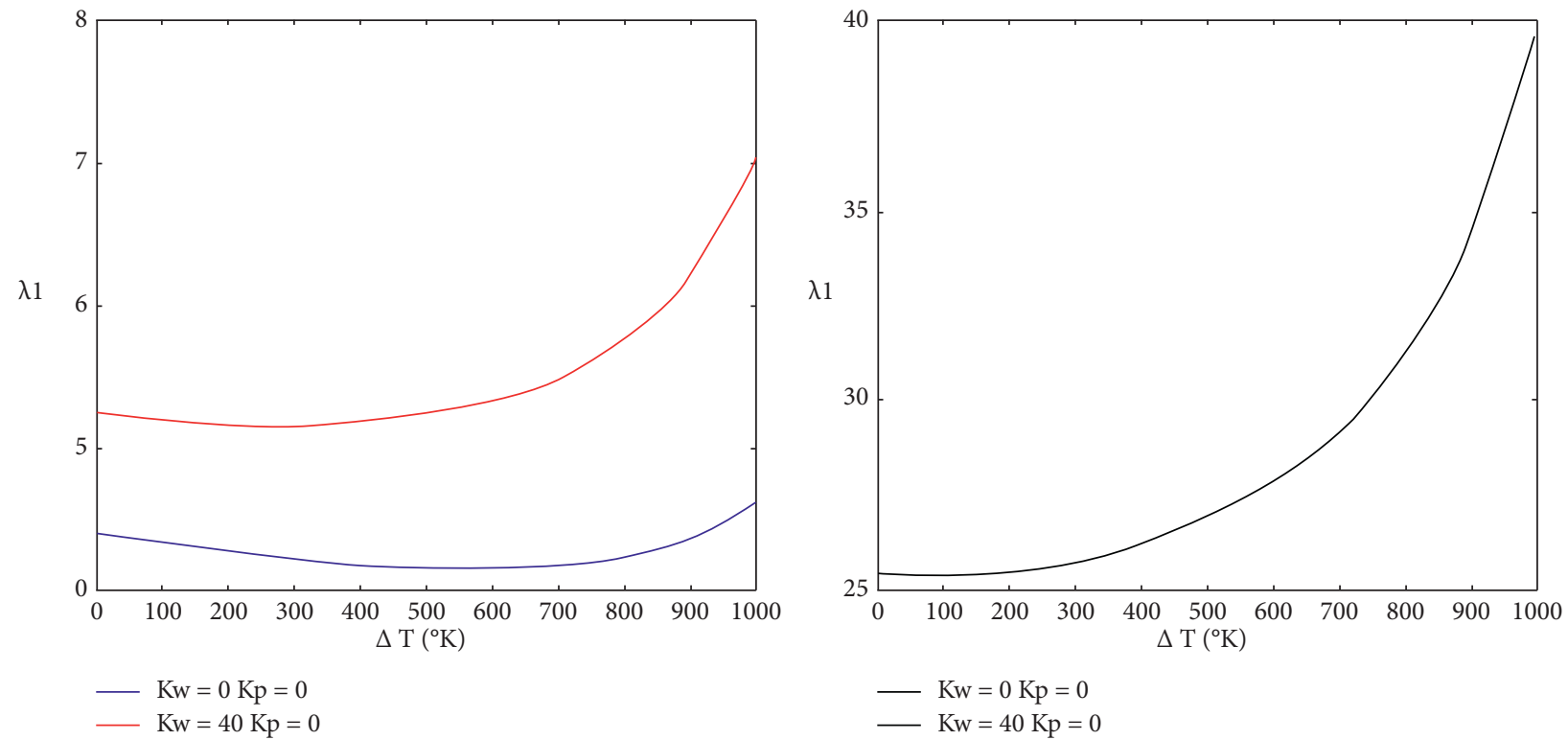

Figure 4: Winkler's and Pasternak's parameters impact on the first nondimensional FG porous beam frequency with the rise in uniform temperature with the simply supported condition. $p=0.5, a=0.2$, and $L / h=5$.

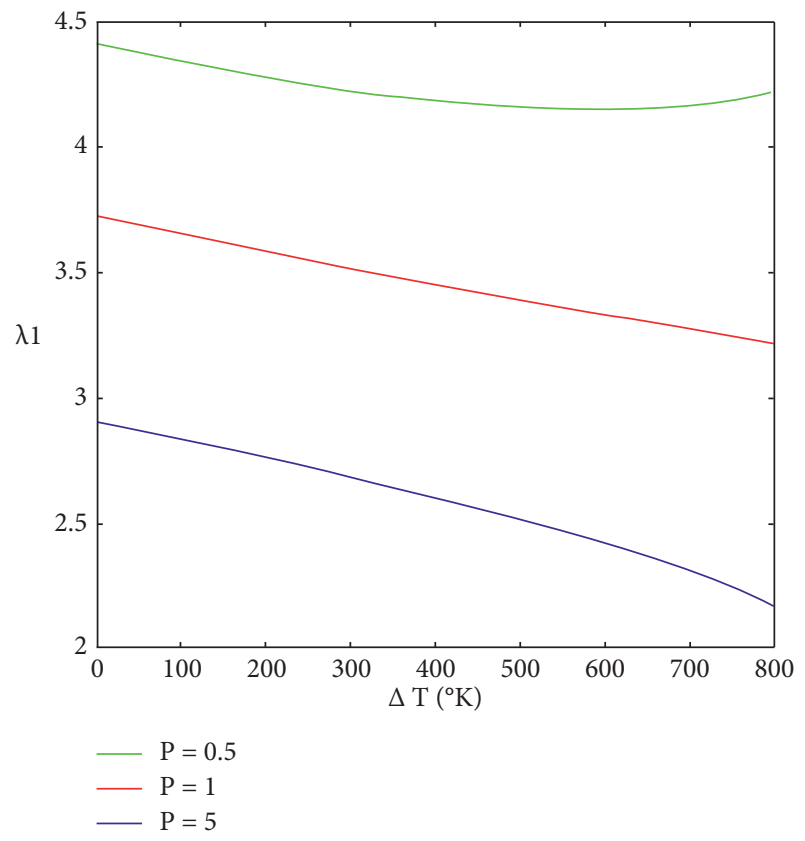

FIGURE 5: Various temperatures differences impact on the first nondimensional FG porous beam frequency with the simply supported condition. $a=0.2$ and $L / h=5$.

index and the porosity coefficient, this trend will increase. In this case, by approaching the ceramic material, this issue will be more evident. Also, with enhancing the power law index, the frequency decreases for a certain temperature variation.

Figure 6 shows the frequency consequences contrary to the different porosity parameters temperature at fixed values of the slenderness ratio and index of power law to display the porosity coefficient impact with a uniform porosity distribution on the natural frequency. Higher natural frequencies

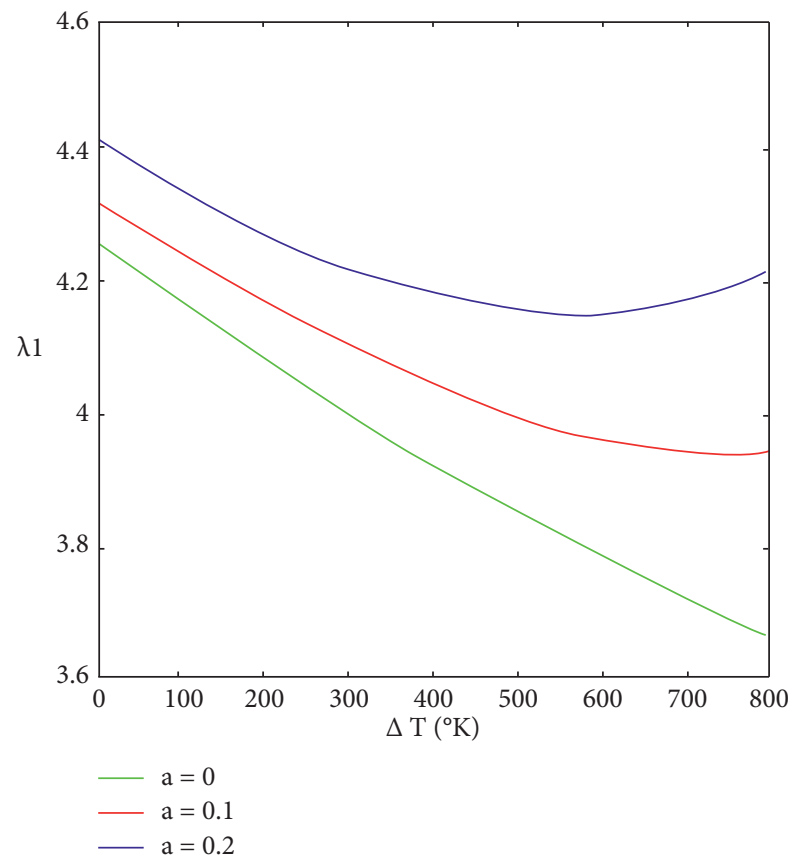

Figure 6: Porosity index impact on the first nondimensional FG porous beam frequency with the simply supported condition and various temperatures differences. $p=0.5$ and $L / h=5$.

are required for a higher value of the porosity coefficient. As shown in Figure 6, for the nonporosity mode, with increasing temperature variation for a thick beam, the natural frequency decreases because of the change in beam stiffness and greater flexibility with increasing temperature. In the case of porous beams, given that porosity can affect all the elasticity modulus, coefficients of inertia density, and other mechanical attributes with observing temperature and 


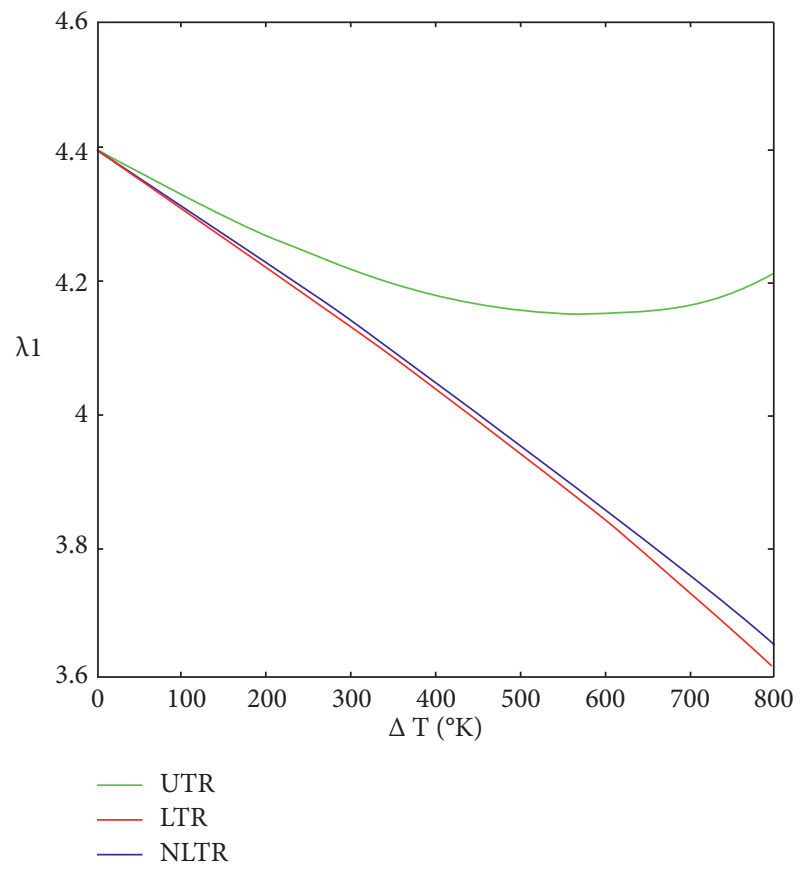

FIgURE 7: Thermal field type impact on the first nondimensional FG porous beam frequency with the simply supported condition and various temperatures differences. $p=0.5, a=0.2$, and $L / h=5$.

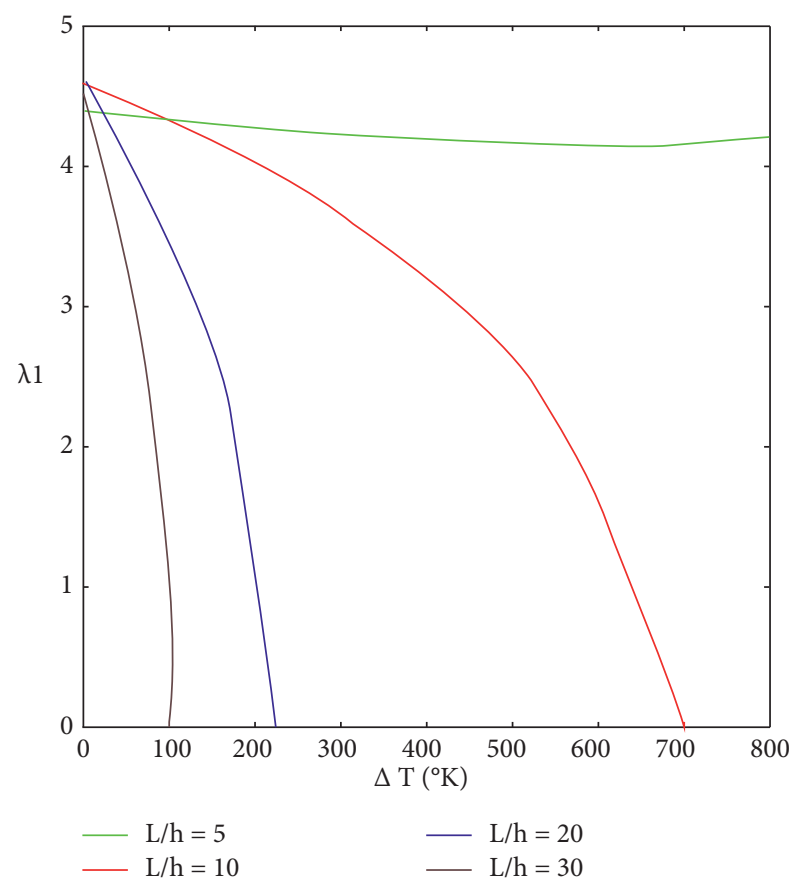

Figure 8: Slenderness ratio effect on the first nondimensional FG porous beam frequency with the simply supported condition and various temperatures difference. $p=0.5$ and $a=0.2$.

power law index, the natural frequency with increasing temperature depending on the power law index value and coefficient of porosity to a point and, from there, with the predominance of the index of power law impact and the coefficient of porosity, can cause this trend increase. For a larger porosity coefficient, this will occur at lower temperature differences.

In Figure 7, the thermal load's effect on frequencies is presented. The uniform porosity distribution of the beam is displayed in three uniform, linear, and nonlinear thermal loads for fixed values coefficient of porosity, slenderness ratio, and index of power law. The frequencies are higher than the other two states for the uniform temperature distribution with various temperatures differences, and the slope of the frequency decreasing variations is smaller. This is due to the greater flexibility of the beam due to the higher temperature of different points in the beam thickness direction.

For different slenderness ratio values and constant values coefficient of the porosity and the index of power law, the differences of the dimensionless natural frequencies of FG beam with the temperature versus a uniform porosity distribution are presented in Figure 8. The beam is exposed in a uniform temperature rise. As shown in the figure, at a high slenderness ratio, thermal buckling occurs at a lower temperature difference. Therefore, the comparison of frequencies should be made below the critical temperature. It is clear, in the figure, that the natural frequencies were higher at a given temperature difference for a smaller slenderness ratio, and this is due to the greater geometric stiffness of the beam with a smaller slenderness ratio.

\section{Conclusion}

This research studies functionally graded beams dynamic behavior with an elastic substrate of two parameters in a temperature-dependent environment and uniform porosity. Temperature-dependent and constant variation in the direction of the beam thickness and the distribution of power law of the material constituents' volume fraction are the material attributes. Uniform, linear, and nonlinear thermal loads are carried out in the direction of beam thickness. For considering the thick beam's vibrational behavior, the theory of third-order shear deformation is used. For the motion equations, Hamilton's principle was administered. For solving the equations of governing, generalized differential quadrature method has been used. The impacts of power law index, type of thermal load porosity coefficient, and beam slenderness ratio on natural beam frequencies were investigated. We can conclude the numerical consequences as follows:

(i) the decrease in frequency, there is an increase in the material index $(p)$.

(ii) The shorter (or thicker) beam has a higher natural frequency.

(iii) the increase in temperature, there is a decrease in natural frequency for nonporous beam, because high temperatures can reduce the material stiffness with fixed mass.

(iv) In the case of porous beams, given the modulus of elasticity, density, coefficients of inertia, and other 
mechanical properties in addition to the observance of temperature and power law index, it can also be affected by porosity. The natural frequency with increasing temperature depending on the value of the power law index and porosity coefficient has been down to a point, and, from there, with the predominance of the effects of the power law index and the porosity coefficient, this trend will increase.

(v) The natural frequency under the uniform increase in temperature for thick functionally graded porous beam is greater than those under the linear and nonlinear increase in temperature.

(vi) The porosity increase will enhance the natural frequency in the distribution of uniform porosity and a certain thermal variation.

(vii) There is a significant effect on the natural frequency by changes in the elastic substrate rigidity. The total system stiffness and, accordingly, the natural frequency are enhanced by increasing both elastic substrate factors. In other words, combining both elastic substrate parameters increases the stiffness and thus increases the natural frequency.

(viii) The presented numerical method is in good agreement with the solution methods in other articles. In other words, generalized differential quadrature method provides very accurate results, and, with fewer divisions, the answer can be reached faster.

\section{Data Availability}

The manuscript is a mathematical method; therefore, no data were used to support this study.

\section{Conflicts of Interest}

The authors declare that they have no conflicts of interest.

\section{References}

[1] Y. Tomota, K. Kuroki, T. Mori, and I. Tamura, “Tensile deformation of two-ductile-phase alloys: flow curves of $\alpha-\gamma$ $\mathrm{Fe} \square \mathrm{Cr} \square \mathrm{Ni}$ alloys," Materials Science and Engineering, vol. 24, no. 1, pp. 85-94, 1976.

[2] A. E. Alshorbagy, M. A. Eltaher, and F. F. Mahmoud, "Free vibration characteristics of a functionally graded beam by finite element method," Applied Mathematical Modelling, vol. 35, no. 1, pp. 412-425, 2011.

[3] K. K. Pradhan and S. Chakraverty, "Free vibration of Euler and Timoshenko functionally graded beams by Rayleigh-Ritz method," Composites Part B: Engineering, vol. 51, pp. 175-184, 2013.

[4] C. Jin and X. Wang, "Accurate free vibration analysis of Euler functionally graded beams by the weak form quadrature element method," Composite Structures, vol. 125, pp. 41-50, 2015, p.

[5] X.-F. Li, "A unified approach for analyzing static and dynamic behaviors of functionally graded Timoshenko and
Euler-Bernoulli beams," Journal of Sound and Vibration, vol. 318, no. 4-5, pp. 1210-1229, 2008.

[6] H. Wu, S. Kitipornchai, and J. Yang, "Free vibration and buckling analysis of sandwich beams with functionally graded carbon nanotube-reinforced composite face sheets," International Journal of Structural Stability and Dynamics, vol. 15, no. 7, Article ID 1540011, 2015.

[7] I. Katili, T. Syahril, and A. M. Katili, "Static and free vibration analysis of FGM beam based on unified and integrated of Timoshenko's theory," Composite Structures, vol. 242, 2020 p, Article ID 112130.

[8] Y. Wen and Q. Y. Zeng, "A high-order finite element formulation for vibration analysis OF beam-type structures," International Journal of Structural Stability and Dynamics, vol. 9, no. 4, pp. 649-660, 2009.

[9] M. Şimşek, "Fundamental frequency analysis of functionally graded beams by using different higher-order beam theories," Nuclear Engineering and Design, vol. 240, no. 4, pp. 697-705, 2010.

[10] M.-J. Kazemzadeh-Parsi, F. Chinesta, and A. Ammar, "Proper generalized decomposition for parametric study and material distribution design of multi-directional functionally graded plates based on 3D elasticity solution," Materials, vol. 14, no. 21 , p. $6660,2021$.

[11] C.-N. Chen, "DQEM vibration analyses of nonprismatic beams resting on elastic foundations," International Journal of Structural Stability and Dynamics, vol. 2, no. 1, pp. 99-115, 2002.

[12] P. Malekzadeh and G. Karami, "A mixed differential quadrature and finite element free vibration and buckling analysis of thick beams on two-parameter elastic foundations," Applied Mathematical Modelling, vol. 32, no. 7, pp. 1381-1394, 2008.

[13] R. Aghazadeh, E. Cigeroglu, and S. Dag, "Static and free vibration analyses of small-scale functionally graded beams possessing a variable length scale parameter using different beam theories," European Journal of Mechanics - A: Solids, vol. 46, pp. 1-11, 2014.

[14] Ş. D. Akbaş, "Free vibration and bending of functionally graded beams resting on elastic foundation," Research on Engineering Structures and Materials, vol. 1, no. 1, pp. 25-37, 2015.

[15] A. Mohseni and M. Shakouri, "Vibration and stability analysis of functionally graded CNT-reinforced composite beams with variable thickness on elastic foundation," Proceedings of the Institution of Mechanical Engineers - Part L: Journal of Materials: Design and Applications, vol. 233, no. 12, pp. 24782489, 2019.

[16] A. Mahi, E. A. Adda Bedia, A. Tounsi, and I. Mechab, "An analytical method for temperature-dependent free vibration analysis of functionally graded beams with general boundary conditions," Composite Structures, vol. 92, no. 8, pp. 1877-1887, 2010.

[17] L. C. Trinh, T. P. Vo, H.-T. Thai, and T.-K. Nguyen, "An analytical method for the vibration and buckling of functionally graded beams under mechanical and thermal loads," Composites Part B: Engineering, vol. 100, pp. 152-163, 2016.

[18] T. T. Thom and N. D. Kien, "Free vibration analysis of 2-D FGM beams in thermal environment based on a new thirdorder shear deformation theory," Vietnam Journal of Mathematics, vol. 40, no. 2, pp. 121-140, 2018.

[19] N. Wattanasakulpong and V. Ungbhakorn, "Linear and nonlinear vibration analysis of elastically restrained ends FGM beams with porosities," Aerospace Science and Technology, vol. 32, no. 1, pp. 111-120, 2014. 
[20] F. Ebrahimi and A. Jafari, "A higher-order thermomechanical vibration analysis of temperature-dependent FGM beams with porosities," Journal of Engineering, vol. 2016, Article ID 9561504, 20 pages, 2016.

[21] H. Ait Atmane, A. Tounsi, and F. Bernard, "Effect of thickness stretching and porosity on mechanical response of a functionally graded beams resting on elastic foundations," International Journal of Mechanics and Materials in Design, vol. 13, no. 1, pp. 71-84, 2017.

[22] M. Heshmati and F. Daneshmand, "Vibration analysis of nonuniform porous beams with functionally graded porosity distribution," Proceedings of the Institution of Mechanical Engineers - Part L: Journal of Materials: Design and Applications, vol. 233, no. 8, pp. 1678-1697, 2019, p.

[23] Ş. D. Akbaş, A. H. Bashiri, A. E. Assie, and M. A. Eltaher, "Dynamic analysis of thick beams with functionally graded porous layers and viscoelastic support," Journal of Vibration and Control, vol. 27, 2020.

[24] C. W. Bert and M. Malik, "Differential quadrature method in computational mechanics: a review," Applied Mechanics Reviews, vol. 49, 1996.

[25] M. Farid, P. Zahedinejad, and P. Malekzadeh, "Three-dimensional temperature dependent free vibration analysis of functionally graded material curved panels resting on twoparameter elastic foundation using a hybrid semi-analytic, differential quadrature method," Materials \& Design, vol. 31, no. 1, pp. 2-13, 2010.

[26] P. Malekzadeh and Y. Heydarpour, "Free vibration analysis of rotating functionally graded cylindrical shells in thermal environment," Composite Structures, vol. 94, no. 9, pp. 2971-2981, 2012.

[27] H. Ersoy, K. Mercan, and Ö. Civalek, "Frequencies of FGM shells and annular plates by the methods of discrete singular convolution and differential quadrature methods," Composite Structures, vol. 183, pp. 7-20, 2018.

[28] Y. Wang, C. Feng, X. Wang, Z. Zhao, C. S. Romero, and J. Yang, "Nonlinear free vibration of graphene platelets (GPLs)/polymer dielectric beam," Smart Materials and Structures, vol. 28, no. 5, Article ID 055013, 2019.

[29] Y. Wang, C. Feng, J. Yang, D. Zhou, and S. Wang, "Nonlinear vibration of FG-GPLRC dielectric plate with active tuning using differential quadrature method," Computer Methods in Applied Mechanics and Engineering, vol. 379, Article ID 113761, 2021.

[30] Y. Wang, Y. Zhou, C. Feng, J. Yang, D. Zhou, and S. Wang, "Numerical analysis on stability of functionally graded graphene platelets (GPLs) reinforced dielectric composite plate," Applied Mathematical Modelling, vol. 101, pp. 239-258, 2022.

[31] MS. Al-Furjan, M. Habibi, J. Ni, D. won Jung, and A. Tounsi, "Frequency simulation of viscoelastic multi-phase reinforced fully symmetric systems," Engineering with Computers, pp. 1-7, 2020.

[32] MS. Al-Furjan, M. Habibi, G. Chen, H. Safarpour, M. Safarpour, and A. Tounsi, "Chaotic simulation of the multi-phase reinforced thermo-elastic disk using GDQM," Engineering with Computers, pp. 1-24, 2020.

[33] A. Shariati, M. Habibi, A. Tounsi, H. Safarpour, and M. Safa, "Application of exact continuum size-dependent theory for stability and frequency analysis of a curved cantilevered microtubule by considering viscoelastic properties," Engineering with Computers, vol. 37, no. 4, pp. 3629-3648, 2021.

[34] X. Huang, H. Hao, K. Oslub, M. Habibi, and A. Tounsi, "Dynamic stability/instability simulation of the rotary size- dependent functionally graded microsystem," Engineering with Computers, pp. 1-7, 2021.

[35] M. S. H. Al-Furjan, A. hatami, M. Habibi, and L. Shan, "On the vibrations of the imperfect sandwich higher-order disk with a lactic core using generalize differential quadrature method," Composite Structures, vol. 257, Article ID 113150, 2021.

[36] MS. Al-Furjan, M. Habibi, A. Ghabussi, H. Safarpour, M. Safarpour, and A. Tounsi, "Non-polynomial framework for stress and strain response of the FG-GPLRC disk using three-dimensional refined higher-order theory," Engineering Structures, vol. 228, Article ID 111496, 2021.

[37] P. Zahedinejad, "Free vibration analysis of functionally graded beams resting on elastic foundation in thermal environment," International Journal of Structural Stability and Dynamics, vol. 16, no. 7, Article ID 1550029, 2016.

[38] H.-T. Thai and T. P. Vo, "Bending and free vibration of functionally graded beams using various higher-order shear deformation beam theories," International Journal of Mechanical Sciences, vol. 62, no. 1, pp. 57-66, 2012.

[39] J. N. Reddy, "A simple higher-order theory for laminated composite plates," Journal of Applied Mechanics, vol. 51, 1984.

[40] H.-S. Shen and Z.-X. Wang, "Nonlinear analysis of shear deformable FGM beams resting on elastic foundations in thermal environments," International Journal of Mechanical Sciences, vol. 81, pp. 195-206, 2014.

[41] Y.-W. Kim, "Temperature dependent vibration analysis of functionally graded rectangular plates," Journal of Sound and Vibration, vol. 284, no. 3-5, pp. 531-549, 2005. 